\title{
Capoeira Angola: um canto de resistência
}

\author{
Carla Alves de Carvalho Yahn ${ }^{1}$
}

RESUMO: Considerando que a Capoeira Angola é uma manifestação de saberes ancestrais e populares transmitidos por meio de cantigas, mitos e fundamentos, este artigo procura colocar em evidência a relação existente entre essa expressão cultural e a Literatura. Para tanto, tomar-se-á como exemplo a Literatura de Cordel, a qual, assim como a Capoeira, traz como tema de seus versos, ou de seus contos rimados, figuras populares como Pedro Cem, Riachão, Besouro, Pedro Mineiro, Valente Vilela, Zumbi, entre outros.

ABSTRACT: Taking into consideration that Capoeira Angola is an expression of popular and ancestral knowledge, which is transmitted by means of ditties, myths, and basis, this paper intend to put in evidence the relationship between this cultural manifestation and literature. For this, it will be taking as example the Cordel Literature, which brings as themes of its verses, or rhymed tales - just as the Capoeira - some popular figures like ones named Pedro Cem, Riachão, Besouro, Pedro Mineiro, Valente Vilela, Zumbi, among others.

PALAVRAS-CHAVE: Capoeira Angola; Cantigas; Poesia; Literatura de Cordel. KEYWORDS: Capoeira Angola; Ditties; Poetry, Cordel Literature.

Balança o mar... balança numa ginga interminável das florestas de Matamba aos serrados dos brasis.

Balança o mar... balança numa dança incansável com o futuro (exercício da destreza necessária).

Balança o mar... balança... é o colo de Kayala que me embala, são os braços de Kyanda - onde entrego minhas forças pra sair renovado!

(ONAWALE, 2006, p. 155-156)

1 Mestranda do curso de Pós-Graduação em Letras da UNESP de Assis, Título da Pesquisa: Capoeira Angola e Literatura Popular: diálogos da tradição oral afrobrasileira. Contato: surfistica@hotmail.com 
A Capoeira Angola é uma manifestação artístico-cultural que abrange o universo da dança, da música, da literatura, do teatro e da arte marcial. Brincadeira mandingueira que revela em si suas indiscutiveis origens africanas. Alguns estudiosos e mestres mais antigos acreditam que ela teve sua origem no $\mathrm{Ngolo}$, ritual ancestral dos negros bantos do sul de Angola. O Ngolo, ou "dança da zebra", conhecido também como Mufico, Efico ou Efundula, é um ritual que marca a passagem das meninas à vida adulta. Nessa dança ritualística dois lutadores competem e o objetivo é atingir o rosto do adversário com o pé, o que condiz com os objetivos do jogo da Capoeira Angola. Nesse jogo o vencedor pode escolher sua esposa entre as meninas iniciadas à vida adulta.

Atualmente a Capoeira Angola vem sendo praticada e buscada em diversas partes do mundo, porém não se deve perder de vista que ela é uma arte de origem africana que se desenvolveu no Brasil. Suas cantigas são em grande parte cantadas na lingua portuguesa do Brasil, e há uma boa parte de palavras de origem africana, como ginga, mandinga, axé, kalunga, nagô, gunga, inquices, dentre muitas outras, algumas já absorvidas na lingua falada em nossa terra, e outras que ainda são menos conhecidas em nosso território.

Basicamente a Capoeira Angola é uma arte popular afro-brasileira que se caracteriza principalmente por sua teatralidade, por sua mandinga, por sua oralidade (cânticos, mitos e ensinamentos) e por sua aparência lúdica, que camufla na dança e na acrobacia diversos movimentos que podem ser mortais, se executados. A Capoeira Angola resiste em suas raizes culturais e em seus fundamentos tradicionais, por isso é considerada muito mais do que uma mera modalidade esportiva, e como o próprio Mestre Pastinha (Vicente Ferreira Pastinha, 1889-1981) falava, "pratico a verdadeira capoeira de angola e aqui os homens aprendem a ser leais e justos. A lei de Angola, que herdei de meus avós, é a lei da liberdade” (Escola de Capoeira “Os Angoleiros do Sertão"). 
É importante frisar desde início que muitas cantigas de domínio público cantadas em rodas de Capoeira Angola, também podem ser cantadas em manifestações culturais de influência africana como o Jongo, os vários Côcos e o Samba de Roda, tanto o carioca como o do Recôncavo e do Sertão Baiano, o Samba de Crioula, dentre outras manifestações artísticas populares.

Como já foi dito, a maior parte dessas cantigas é expressa em língua portuguesa, o que, ao lado da navalha e do pandeiro, demonstra o quanto a influência portuguesa também está presente nessa arte, pois foram os lusitanos que introduziram esses elementos em nossa cultura. Há algumas cantigas expressas em línguas de origem africana, o que revela a resistência dos negros trazidos do outro lado do Atlântico e a importância dos mesmos, na formação da Capoeira Angola também no que se refere à questão linguística.

O cantador de roda de Capoeira é uma espécie de griot, o contador de histórias que mantém a tradição oral de geração a geração. Os principais subgêneros de cânticos expressos na roda de Capoeira Angola são as ladainhas ou hinos, as louvações ou chulas, as quadras e os corridos. A ladainha geralmente é mais longa que os outros cânticos, ela pode ter diversas funções, pode ser um apelo, uma vocação, uma sátira, tratar de temas de amor ou heróicos, pode ser uma narrativa histórica, uma denúncia social, um agradecimento e muito mais. A louvação é um momento de exaltação, nela pode-se exaltar Deus, uma determinada terra, uma determinada pessoa, uma ação, alguns instrumentos como a faca de ponta, por exemplo. É na louvação que fica muito claro a aproximação dos cânticos de Capoeira com o sagrado. As quadras são versos compostos geralmente por rimas alternadas, falam de temas diversos e, na maioria das vezes, são cantigas trabalhadas e elaboradas de forma a dar uma impressão estética bastante interessante. Os corridos é o sinal verde para o jogo da Capoeira, quando eles são cantados os capoeiristas podem "vadiar", são cânticos que assim como a ladainha tratam de temas diversos, podem ser de domínio público, espontâneos e improvisados ou anteriormente 
elaborados e trabalhados. Dentro de tudo isso, pode-se encontrar vários tipos de cantigas, como as de mal dizer e escárnio, as de amor, as de devoção, as agiológicas (que se referem com detalhes a santos católicos ou personagens bíblicas), as de sotaque e desafio, as geográficas e de louvação. Em caráter demonstrativo segue abaixo uma ladainha de domínio público muito cantada nas rodas de capoeira:

Dona Isabel que história é essa

Dona Isabel que história é essa

De ter feito a abolição?

De ser princesa boazinha

Que libertou a escravidão...

Eu tô cansado de conversa,

Eu tô cansado de ilusão,

Abolição se fez com sangue

Que inundava esse pais

Que o negro transformou em luta

Cansado de ser infeliz

Abolição se fez bem antes

Ainda por se fazer agora

Com a verdade da favela

Não com a mentira da escola

Dona Isabel chegou a hora

De acabar com essa maldade

De ensinar a nossos filhos

O quanto custa a liberdade

Viva a Zumbi nosso rei negro

Se fez herói lá em Palmares

Viva a cultura desse povo

A liberdade verdadeira

Que já corria nos quilombos

E já jogava capoeira

Iê maior é Deus...

$\mathrm{Na}$ ladainha exposta acima fica bastante clara a preocupação política e social do cantador da Capoeira Angola. É interessante notarmos que nesse texto temos a voz do próprio negro expressando sua condição e 
reivindicando sua verdadeira história e memória. Aqui Zumbi dos Palmares, organizador do maior quilombo que durou mais de um século e que só foi vencido pelo fato de no último ataque ter sido covardemente atacado por canhões trazidos da Europa, é reverenciado e julgado o verdadeiro responsável pela abolição da escravidão no Brasil, homem que foi capturado e morto principalmente pelo fato de ter sido traído por um dos seus. O texto oral também faz referência à lei Áurea, contestando os verdadeiros interesses que levaram a princesa Isabel a assinar tal documento. Dá ênfase à importância da luta dos negros em busca da liberdade, destacando o heroísmo e a dor pela imagem do sangue que era derramado pelos guerreiros, deixa transparecer o papel fundamental da capoeira, símbolo da força e da vitalidade dos negros que aperfeiçoavam suas habilidades bélicas dentro do quilombo.

Nesse texto oral pode-se destacar ainda a consciência do cantador quanto a sua história, ele sabe que muita luta se deu e continua se dando, tem plena concordância de que ainda tem muito por se fazer, mais do que resistência, precisa-se buscar uma afirmação política. Tudo isso nos faz perceber o quanto as cantigas da Capoeira podem ser um belo instrumento para estudo das formas de Literatura Oral herdadas dos nossos ancestrais e seus descendentes, principalmente vindos de Angola. Além disso, é uma rica manifestação artística que preserva a tradição da oralidade, que em parte se perdeu com o cruel desenraizamento dos negros que foram tirados de sua terra, de seus avós, pais, costumes e história, causando uma reconfiguração cultural africana no Brasil. Ou seja, a capoeira e seus fundamentos fazem parte da reconstrução da identidade negra no Brasil, onde se mantém o princípio da oralidade e da ancestralidade.

Apenas para comparação e demonstração de como as cantigas de capoeira podem ser olhadas como parte da poesia afro-brasileira, segue abaixo um soneto de Eduardo de Oliveira:

Palmares da esperança

Hoje o meu povo, em épica atitude,

Luta feroz! Feroz e não se cansa,

Levantando Palmares de esperança 
- legado dos avós à juventude!

É a consciência da Heróica Negritude

Que exerce seu direito de cobrança!

Negro Zumbi que resoluto avança

Por sobre o algoz como um guerreiro rude!

Dá combate! Protesta! Vocifera

Furioso, qual se fora uma pantera

Que ao estraçalhar a poderosa presa,

Ergue a sua carcaça, que é um troféu,

Para mostrar às amplidões do céu

Que a sua causa é justa e tem grandeza!

(OLIVEIRA, 2006, p. 89)

A partir do soneto apresentado pode-se notar o diálogo com a temática da ladainha anteriormente versada. O soneto explora uma temática condizente com a observada na cantiga de roda de capoeira. Ambas tratam da memória da batalha dos negros em solo brasileiro, da coragem, da sede de liberdade, e da força, vista através da resistência e da vitalidade desses homens que construíram boa parte de nossa nação. Zumbi é visto como herói negro, guerreiro, símbolo da garra, da organização e da união negra. É eternizado nos dois textos, e no último não apenas foi, como é, é o mesmo Zumbi em outros homens e mulheres negros, que ainda lutam e vencem batalhas, filhos dos filhos do Zumbi que ainda avança na batalha pela igualdade e pela dignidade.

No universo da capoeira há muitas figuras míticas e legendarias como Zumbi, outro personagem marcante para os capoeiras é Besouro Preto, conhecido também como Besourinho Cordão de Ouro e Besouro Mangangá. Atualmente podem-se encontrar diversos artigos de divulgação da lenda de Besouro, como filmes, documentários, obras literárias, canções e, em fonte mais tradicional, cantigas de capoeira e depoimentos populares. De forma bastante resumida: Besouro foi um valentão capoeirista que todos temiam. Era o pai dos injustiçados e o terror da polícia e da elite. Aparece dentro das rodas de Capoeira como 
homem místico de corpo fechado. Era mágico, fazia soldado voltar bêbado para o quartel, dava rabo-de-arraia numa tropa inteira e depois desaparecia, diz a lenda que ele se transformava num Besouro e voava. Era o mais mandingueiro, tinha proteção espiritual. Tinha cravado na sua pele a fava da índia, de encanto que só poderia ser quebrado por três elementos: a faca de ticum (árvore encontrada no Brasil), a briga depois de ter deitado com mulher e ter passado debaixo de arame farpado. Numa ocasião Besouro bate no filho de uma autoridade e é tido por morto. Segundo a lenda, no dia de sua morte Besouro deitou-se com uma de suas raparigas, que havia sido paga por essa autoridade para tirar seu patuá, passou por debaixo de arame farpado e brigou com policiais, e um deles trazia a faca de ticum capaz de feri-lo. Besouro viaja muito tempo de canoa à procura de socorro. Socorrido, Besouro recebe a notícia de que não seria mais o mesmo. Então se recusa a viver e morre. A cantiga a seguir fala de Besouro:

\author{
Besôro stava dormindo \\ Acordô todo assustado \\ Deu um tiro in baraúna \\ Pensando qui era sordado. \\ (REGO, 1968, p. 123-124)
}

Nesses versos aparece a figura de Besouro agitado e atordoado. Mesmo na hora do descanso, no tempo que tira para dormir, continua desconfiado e reage ao persecutório. Sempre na ofensiva, ante qualquer barulho ou movimento, atira com firmeza em seu alvo. É importante destacar-se que nessa citação de Waldeloir Rego, a figura de Besouro é confundida com a de Lampião, pois este sim andava armado e sempre desconfiado de soldados. Já segundo a lenda de Besouro, ele não precisava de armas de fogo, sua maior defesa era espiritual, além disso, existe uma outra versão dessa quadra em que Lampião é cantado no lugar de Besouro, isso é um fenômeno comum em rodas de capoeira, as versões de suas cantigas são diversas, variam de região para região, de grupo para grupo. 
Além dessa quadra cantada geralmente em rodas de capoeira, podemos também encontrar textos da literatura de Cordel em que está presente a fascinante saga de Besouro:

\author{
Nas rodas de capoeira \\ Seu nome é muito cantado \\ Fora das rodas também \\ Ele é sempre lembrado \\ Como um grande capoeira \\ Que tinha o corpo fechado \\ Dizem que era valente \\ E bravo como um touro \\ O chamavam "Besouro Preto" \\ Besouro "Cordão de Ouro" \\ De "Besouro Mangangá" \\ Ou simplesmente "Besouro" \\ (ALVIM, Cordel, s. d.)
}

Nessas duas estrofes a figura de Besouro aparece bem coerente com sua lenda, lenda que ainda hoje é contada por diversas pessoas de comunidades populares da região do nordeste brasileiro, principalmente da região de Santo Amaro, no sertão da Bahia. Esses versos são trechos do cordel de Victor Alvim, que com simplicidade declara a forte presença do mito de Besouro no imaginário popular e como ele ainda habita a memória de muitas pessoas, revelando as múltiplas facetas dessa figura, manifestas pelos apelidos e características marcantes que ela possui.

Além de Besouro há também outras figuras lendárias que são muito cantadas em rodas de capoeira, como o mito de Riachão, Pastinha, Cobrinha Verde, dentre alguns outros grandes capoeiristas do Brasil, que também podem ser estudadas.

Pretendeu-se olhar os cânticos da capoeira, seus mitos e ensinamentos como instrumento de transmissão de uma tradição ancestral, que resiste até hoje, que enriquece a oralidade afro-brasileira com suas memórias e criações populares. 


\section{Referências bibliográficas}

GARCIA, Victor Alvim. Histórias e bravuras de Besouro/ o valente capoeira. Cordel. S. 1., s. e., s. d.

REGO, Waldeloir. Capoeira Angola/ ensaio sócio-etnográfico. Bahia: Itapoá, 1968.

OLIVEIRA, Eduardo de. "Palmares da esperança" In: Cadernos negros/poemas afro-brasileiros. Volume 29. São Paulo: Quilombhoje, 2006.

ONAWALE, Lande. "Kalunga" In: Cadernos negros/poemas afro-brasileiros. Volume 29. São Paulo: Quilombhoje, 2006. 